\title{
Not just carbon widgets
}

\author{
Forests are important for the global carbon cycle, and for mitigating greenhouse gas emissions. However, \\ the role forests play in carbon sequestration should not eclipse everything else we value them for.
}

Trees effectively lock $\mathrm{CO}_{2}$ in woody biomass, so it is no surprise that we often think of forests as serving as storehouses of carbon. But forests are complex ecosystems. For example, they have substantial influence over the carbon cycle, the hydrological cycle, local and regional climate, atmospheric chemistry, the emergence and transmission of disease to human populations, provision of timber and agricultural goods, and the maintenance of biodiversity. Adding to the complexity, these processes do not respond equally to anthropogenic pressures. For example, human disturbance of forests in Brazil has a much larger impact on biodiversity than it does on forest cover ${ }^{1}$. In these instances, human disturbance only mildly affects these forests' ability to take up and sequester carbon, but it has a devastating impact on biodiversity. This type of work highlights how even if we can protect the forest carbon sink, we must not lose sight of the tremendous value forests provide in other ways.

Forests are currently a net sink for atmospheric carbon. The global reach of forests is perhaps most impressively illustrated in the time series of global atmospheric $\mathrm{CO}_{2}$ concentrations since 1958, known as the Keeling Curve after Charles Keeling, who started and then directed the observations at the Mauna Loa Observatory. Embedded in the long-term increase in $\mathrm{CO}_{2}$ concentrations is an annual zigzag, with $\mathrm{CO}_{2}$ concentrations decreasing during the boreal summer, and increasing during the boreal winter. This up-and-down seasonal pattern is largely the result of the seasonal carbon cycle of Northern

Hemisphere forests outstripping that of forests in the Southern Hemisphere.

Mitigating climate change and understanding future carbon cycle and climate trajectories are urgent and important. But there is more to forests than their function as carbon capture and storage devices. In addition to sequestering carbon, forests are central to the functioning of many regions ofw the globe. For example, the Amazon rainforest influences the climate and hydrology of the region, as it contributes to regional precipitation ${ }^{2}$ and helps to initiate the onset of the rainy season ${ }^{3}$. Avoiding deforestation - and related forest fires - helps mitigate air pollution and avoid premature deaths $s^{4,5}$.

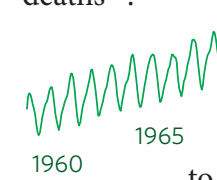$$
1970
$$

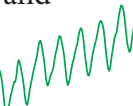
1980 1975 also provide also provide 1960 to people, but these benefits ar only recently being considered explicitly as ecosystem services ${ }^{6}$.

Valuing the remarkable diversity of flora and fauna in its own right has been supplemented - and to some small extent, perhaps supplanted - by the realization that biodiversity supports ecosystem functioning ${ }^{7}$. Highlighting this importance of biodiversity provides additional incentives for protecting it. Although research on biodiversity and ecosystem services has focused on multiple services, evaluations of biodiversity controls over primary

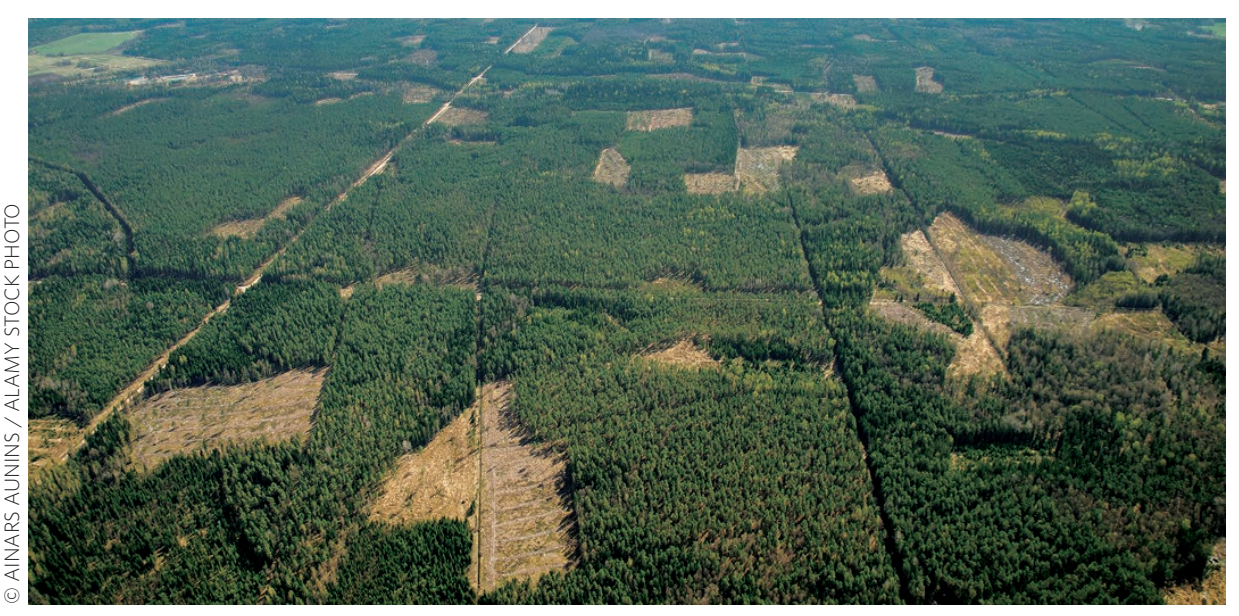

productivity - and hence carbon uptake - are the most common ${ }^{7}$.

A focus on carbon may disguise the fragility of other important ecosystem properties, even when carbon uptake is robust. It is possible for forest cover and regional stocks

\section{0} Just as forest disturbance had much larger effects on biodiversity than on forest cover in Brazil ${ }^{1}$, different forest processes may respond differently to external pressures. In North America, invasive herbivores and disease have changed forest community composition, leading to changes in volatile organic compound emissions from forests and knock-on effects on air quality $^{8}$. Fragmentation of forest increases the risk of transmission of Lyme disease to human populations in suburban and periurban environments in the northeastern United States ${ }^{9}$ and may be important for infectious disease emergence more generally ${ }^{10}$.

Understanding the past, current and future role of forests in the carbon cycle remains an important priority. But it is also important not to assume that forests are healthy if they are effective as carbon capture and storage machines. To ensure that forests continue to provide homes for biodiversity, to supply sources of cultural and spiritual enrichment, to maintain climate and air quality, and to limit risk of disease, it is essential to consider these ecosystems in their full complexity. If we don't, we risk diminishing our world, and ourselves.

\footnotetext{
References

1. Barlow, J. et al. Nature 535, 144-147 (2016).

2. Elathir, E. A. B. \& Bras, R. L. Q. J. Roy. Meteor. Soc 120, 861-880 (1994).

3. Fu, R. \& Li, W. Theor. Appl. Climatol. 78, 97-110 (2004).

4. Marlier, M. E. et al. Nature Clim. Change 3, 131-136 (2013).

5. Reddington, C. L. et al. Nature Geosci. 8, 768-771 (2015).

6. Daniel, T. C. et al. Proc. Natl Acad. Sci. USA

109, 8812-8819 (2012)

. Balvanera, P. et al. Ecol. Lett. 9, 1146-1156 (2006)

8. Geddes, J. A., Heald, C. L., Silva, S. J. \& Martin, R. V. Atmos. Chem. Phys. 16, 2323-2340 (2016).

9. Allan, B. F., Keesing, F. \& Ostfeld, R. S. Conserv. Biol. 1, 267-272 (2003).

10. Patz, J. A. et al. Environ. Health Persp. 112, 1092-1098 (2004).
} 